\title{
El franquismo ante el proceso de Burgos ${ }^{1}$
}

\section{Franco's Regime in the Wake of the Burgos Trial}

\author{
Gaizka Fernández Soldevilla ${ }^{2}$ \\ Centro Memorial de las Víctimas del Terrorismo (España) \\ José Francisco Briones Aparicio ${ }^{3}$ \\ Juzgado Togado Militar Territorial 43, Burgos (España)
}

Recibido: 02-05-20

Aprobado: 03-06-20

\section{Resumen}

El 3 de diciembre de 1970 se inició el proceso de Burgos, en el que se juzgó a dieciséis miembros de ETA. Hubo seis condenados a muerte, aunque su pena sería conmutada. A menudo el sumarísimo 31/69 ha sido interpretado como un golpe de fuerza de la dictadura, que habría cometido un error estratégico y finalmente habría sido derrotada por la movilización masiva contra las ejecuciones. El proceso de Burgos fue un fenómeno complejo que necesita ser reexaminado. Gracias a las fuentes primarias, comprobamos las divergencias que hubo en el seno del franquismo, que en los años siguientes no harían sino crecer.

Palabras-clave: ETA, terrorismo, proceso de Burgos, franquismo, 1970.

\footnotetext{
${ }^{1}$ Los autores desean agradecer las útiles sugerencias y aportaciones de José Luis de la Granja, Florencio Domínguez, Jesús Casquete, Raúl López Romo, Liviana Bucureșteanu, Abel García y David Mota. Este artículo se ha realizado en el marco del programa de investigación del Centro Memorial de las Víctimas del Terrorismo, del GIR Humanidades y Ciencias Sociales en la Era digital y tecnológica de la Universidad Isabel I y del proyecto de investigación de la UPV-EHU, que dirige Coro Rubio Pobes, PGC2018-094133-B-100 (MCIU/AEI/FEDER, UE).

2 (investigacion@centromemorialvt.com) Responsable de Archivo, Investigación y Documentación del Centro para la Memoria de las Víctimas del Terrorismo. Doctor en Historia Contemporánea.

ORCID: https://orcid.org/0000-0002-7574-1159

3 (jbriapa@ea.mde.es) Auxiliar del Juzgado Togado Militar Territorial n 43 (Burgos), de cuyo archivo es responsable.
} 


\begin{abstract}
On 3 December 1970 the Burgos Trial began, with sixteen members of ETA held for prosecution. There were six death sentences that nonetheless were further commuted. Often the summary proceeding 31/69 was understood as a coup de force of the regime, the latter having committed a strategic mistake which would soon bring defeat upon itself caused mainly by the mass protests against the executions. The trial of Burgos was a complex phenomenon which needs a closer examination. With the help of original sources we were able to verify what caused the breach within the Francoism, crack which in the following years would only grow bigger.
\end{abstract}

Key-words: ETA, Terrorism, Burgos Trial, Francoism, 1970.

\title{
Introducción
}

El 3 de diciembre de 1970 dio comienzo en Burgos, sede de la Capitanía General de la VI Región Militar, la vista de la causa sumarísima $n^{\circ}$ 31/69. Los imputados eran miembros de Euskadi ta Askatasuna (País Vasco y Libertad, ETA). Ellos y sus abogados aprovecharon la presencia de corresponsales extranjeros para deslegitimar a la dictadura, dar a conocer el nacionalismo vasco radical y despertar las simpatías de un amplio sector de la ciudadanía. Pero, como se verá, el proceso de Burgos no solo brindó a los etarras una victoria propagandística, sino también su resurrección operativa. No es de extrañar que John Sullivan lo considerase "el suceso más trascendental de la historia de ETA" ${ }^{4}$.

El consejo de guerra encontró a la mayoría de los acusados culpables de delitos como tenencia ilícita de armas, robo a mano armada, rebelión militar, terrorismo y, en un caso, asesinato. ETA presentó el sumarísimo $31 / 69$ como un ataque contra toda la nación vasca por parte de su enemigo ancestral, España. Se trataba de una interpretación oportunista y parcial, pero resultó efectiva: convenció 5 .

Gracias a su campaña publicitara y al eco que tuvo en la prensa, la versión de ETA se hizo hegemónica en determinados ámbitos. Uno de los ejemplos más tempranos fue la publicación de El proceso de Euskadi en Burgos (1971), de dos de los abogados defensores, Miguel Castells y Francisco Letamendia, en el que se proclamaba que "en Burgos se juzga a Euskadi". Iba en la misma línea que la obra firmada por Gisèle Halimi, que apareció al año siguiente con prólogo de Jean-Paul Sartre. En 1975

\footnotetext{
${ }^{4}$ Sullivan 1988: 111; Casquete 2012.

${ }^{5}$ Fernández 2016: 23-61.
} 
Letamendia introdujo una variante al aseverar que el "escarmiento público" del consejo de guerra había sido instrumentalizado por el Gobierno para "distraer la acción de las masas". En 1978 el sello Hordago editó un libro con el elocuente título de Burgos: juicio a un pueblo. En la historia oficiosa de ETA (1993) se puede leer que se trató de "un juicio contra el pueblo vasco, donde lo que se juzgaba era todo un proyecto nacional". En otro trabajo Letamendia insistía en que el consejo de guerra había sido un “juicio-escarmiento". Para Iñaki Egaña Sevilla también fue una "prueba de escarmiento" planteada por el "sistema español”. Más recientemente Iker Casanova ha defendido que la "intención" del sumarísimo 31/69 "era escenificar públicamente la liquidación de ETA y la victoria del Estado sobre la incipiente insurgencia armada vasca". Sin embargo, no se trataría de "un grupo aislado", sino que representaba al "pueblo vasco".

Todavía hoy se siguen reproduciendo algunos de los elementos de esta narración. En resumen, el proceso de Burgos habría sido diseñado por el régimen, visto como un todo unido, monolítico y coherente. El franquismo habría resuelto que se dictasen y cumpliesen irremisiblemente las penas capitales, ya que el objetivo del consejo de guerra era castigar y someter a la nación vasca, que también es imaginada como uniformemente antifranquista y abertzale (patriota). Solo las intervenciones de los acusados, las presiones internacionales, el secuestro de Eugen Beihl, cónsul de la República Federal Alemana (RFA) en San Sebastián, y las masivas movilizaciones habrían dado al traste con los planes del Gobierno de Franco, quien se habría visto forzado a la conmutación de las condenas de muerte.

Con estos mimbres se ha construido una especie de mito que constituye un relato heroico, conmovedor y fácilmente comprensible. No obstante, está tergiversado, es dicotómicamente maniqueo, oculta hechos importantes, como el origen de ciertas iniciativas para evitar las ejecuciones, y simplifica los acontecimientos.

Durante décadas el peso del mito ha lastrado los estudios acerca del proceso de Burgos, pero cada vez hay más trabajos académicos que van más allá, como los de Andrés Zaragoza y Jesús Casquete ${ }^{7}$. Siguiendo su estela, el presente artículo pretende acercarse a un aspecto que la historiografía aún no había tratado en profundidad: el papel que jugaron los distintos estamentos de la dictadura en el consejo de guerra y las secuelas que este dejó en su interior. Estamos en condiciones de acometer dicha tarea por medio de la bibliografía académica, la documentación gubernativa, las causas judiciales, las memorias de Mario Onaindia, Eduardo Uriarte (Teo),

${ }^{6}$ Salaberri 1971; Halimi 1972; Letamendia 1975: 456; Lurra 1978; Núñez 1993 vol. III: 48 y 51; Letamendia 1994 vol. I: 349; Egaña 1996: 116; Casanova 2010: 118.

7 Zaragoza 1993; Casquete 2012.

Araucaria. Revista Iberoamericana de Filosofia, Política, Humanidades y Relaciones Internacionales, año $22, \mathrm{n}^{\circ} 44$. Segundo semestre de 2020. Pp. 27-51. ISSN 1575-6823 e-ISSN 2340-2199 https://dx.doi.org/10.12795/araucaria.2020.i44.02 
Laureano López Rodó, José Sainz y Andrés Cassinello, inéditas estas dos últimas, y el testimonio de Antonio Troncoso. Sin embargo, antes se hará un repaso somero de la historia de la primera ETA.

\section{De las primeras bombas al cisma de 1970}

Nacida entre 1958 y 1959, a juicio de José María Garmendia, ETA siempre tuvo presente "la necesidad de practicar la violencia". Lo fue haciendo gradualmente, paso a paso. En octubre y noviembre de 1959 puso sus primeras tres bombas, que no reivindicó. El 18 de julio de 1961 unos etarras quemaron banderas rojigualdas en San Sebastián e intentaron, sin lograrlo, hacer descarrilar un tren de excombatientes guipuzcoanos que acudían a conmemorar el $25^{\circ}$ aniversario del "Alzamiento Nacional". El 6 de diciembre de 1963 tres integrantes de ETA le dieron una paliza al maestro de Zaldívar. Dos años después ETA adoptó como estrategia la espiral de acción-reacción-acción: realizar actos de violencia que provocasen una represión desproporcionada que afectase a toda la población vasca, que así se adheriría a su causa y a la "guerra revolucionaria".

A partir de 1967 ETA efectuó atracos con éxito, lo que le permitió adquirir armamento e infraestructura, así como mantener económicamente a sus líderes. Se colocaron bombas en medios de comunicación, propiedades de personas acusadas de colaborar con las Fuerzas de Orden Público (FOP), repetidores, ayuntamientos, locales sindicales, cuarteles, símbolos franquistas... El 2 de junio de 1968 la dirección de ETA tomó la resolución de asesinar a José María Junquera y Melitón Manzanas, los jefes de la Brigada de Investigación Social de Bilbao y San Sebastián respectivamente. El encargado de planificar el atentado contra Manzanas era Txabi Echebarrieta. Cinco días después, en un control de tráfico rutinario, Echebarrieta y su compañero Iñaki Sarasketa asesinaron al guardia civil José Antonio Pardines. A las pocas horas se produjo un enfrentamiento armado entre los dos etarras y una pareja de la Benemérita, en el que fue abatido Echebarrieta9 9

Junquera se salvó por no encontrarse en casa, pero el 2 de agosto de 1968 un integrante de ETA mató a Manzanas en Irún. Responsable de reprimir a la oposición y torturador, su asesinato fue bien recibido por las fuerzas antifranquistas. Tal y como estaba previsto, se puso en marcha la espiral de acción-reacción-acción: la dictadura respondió a la provocación con una represión brutal e indiscriminada. El Gobierno declaró un estado

\footnotetext{
${ }^{8}$ Garmendia 1996: 152; Fernández y Domínguez 2018.

9 Fernández y Domínguez 2018.
} 
de excepción en Guipúzcoa, que ampliaría a toda España. Se multiplicó el número de detenidos y los malos tratos ${ }^{10}$.

ETA colocó catorce bombas en la Semana Santa de 1969. La prolongación de la campaña permitió a las FOP ampliar la información sobre el grupo. El 9 de abril de 1969 algunos dirigentes etarras cayeron en Bilbao: Josu Abrisketa Korta (Txutxo), Víctor Arana Bilbao y Mario Onaindia. Otro, Miguel Etxeberria Iztueta (Makagüen), escapó del cerco policial asesinando al taxista Fermín Monasterio Pérez. Dos días después el resto de la cúpula de ETA fue arrestada en la localidad cántabra de Mogrovejo: Teo Uriarte, Jon Etxabe, Enrique Gesalaga y Jone Dorronsoro ${ }^{11}$.

En palabras de Gurutz Jáuregui, "ETA pasa por el peor momento de su historia. La confusión es absoluta, hasta el punto de que, en algún momento, se habla de la disolución de la organización". Descabezada, sus contradicciones salían a la luz. Por un lado, la espiral de acción-reacciónacción no produjo ningún levantamiento de las masas. Por otro lado, en el seno de la banda había tendencias enfrentadas por la disyuntiva entre nacionalismo/violencia o marxismo/obrerismo. La dirección provisional consiguió que se aprobaran sus tesis izquierdistas en la VI Asamblea (agosto de 1970), aunque la consecuencia fue el cisma. El grueso de la militancia, que fue fiel al Ejecutivo, sería conocido como ETA VI, grupo que evolucionó hacia la extrema izquierda. La facción anticolonialista y el frente militar, de tendencia ultranacionalista, no reconocieron la "legalidad" de la VI Asamblea y se escindieron para formar ETA $\mathrm{V}^{12}$.

El intento de ETA VI de sacar de la cárcel a los imputados en el proceso de Burgos resultó un fracaso. Además, tras ciertas dudas, la mayoría de estos apoyaron a ETA V, que en diciembre de 1970 secuestró al cónsul de la RFA en San Sebastián, lo que supuso un triunfo propagandístico a nivel internacional. En 1972 ETA V se fusionó con EGI-Batasuna (Unidad), la facción más extremista de las juventudes del PNV. A partir de entonces fue la única ETA.

\section{El consejo de guerra}

El tribunal militar estuvo presidido por el teniente coronel Manuel Ordovás González. Su experiencia jurídica más reseñable había sido la presidencia del sumarísimo 28/69 contra el miembro de ETA Andoni Arrizabalaga. No obstante, quien llevó el peso tanto de aquel juicio como

\footnotetext{
10 Casanellas 2014.

11 Garmendia 1996: 368-375; Uriarte 2005: 98-100.

12 Jáuregui 2006: 258; Fernández 2016: 191-192.
} 
del proceso de Burgos fue el capitán Antonio Troncoso de Castro, del Cuerpo Jurídico Militar, que ejercía de vocal ponente ${ }^{13}$.

Al otro lado había personas muy preparadas, como unos años después demostraría su papel en la vida política. Entre los imputados estaban Mario Onaindia, Teo Uriarte, Gregorio López Irasuegui, Itziar Aizpurua y Jokin Gorostidi. También tendrían proyección sus abogados: Josep Solé Barberá, Gregorio Peces-Barba, José Antonio Etxebarrieta, Juan Mari Bandrés, Miguel Castells y Francisco Letamendia.

Según el concordato entre la dictadura y el Vaticano (1953), los sacerdotes tenían derecho a que se les juzgase a puerta cerrada. Los dos curas encausados, Julen Calzada y Jon Etxabe, así como sus obispos de Bilbao y San Sebastián, se negaron a ejercer ese privilegio. Después de una disputa entre la justicia militar y la jerarquía eclesiástica, el proceso terminó celebrándose en audiencia pública. Era un síntoma de la desafección de un significativo sector de la Iglesia católica, que desde la Guerra Civil había sido sostén del régimen ${ }^{14}$.

Aprovechando la presencia de la prensa en la sala y gracias a una escenificación planeada por Mario Onaindia, los acusados y sus abogados defensores convirtieron sus intervenciones en una denuncia global de la dictadura. Las opiniones de los expertos son unánimes. En palabras de Garmendia se trató de "un auténtico hito de la lucha antifranquista". Sullivan cree que "el resultado del juicio fue una derrota moral y política para el régimen de Franco". Siguiendo a Alejandro Muñoz Alonso, "nadie vio a los procesados como unos separatistas en lucha contra España, sino a unos heroicos luchadores contra una dictadura brutal"15.

Los medios de comunicación contribuyeron a su idealización y a la difusión de su mensaje. Juan Mari Bandrés recordaba que los abogados "mantuvimos una gran libertad en las ruedas de prensa, hay que reconocer que dábamos unas ruedas de prensa de puta madre". En su tesis doctoral Teo Uriarte afirma que "la batalla informativa internacional la perdió el régimen de Franco", el cual "tuvo la osadía de responderla desde su reducto ideológico más reaccionario, la ideología derrotada en Europa en 1945, y ello sirvió para recordar a la opinión pública mundial la existencia de una situación política no resuelta como la española". A decir de Javier Tusell, "la reacción de los medios gubernamentales resultó tardía y contraproducente" 16 .

\footnotetext{
13 Sumarísimo 31/69, 1970, Archivo Judicial Territorial de la Comunidad de Madrid (AJTCM).

14 Pablo 2015: 379.

15 Casquete 2012; Garmendia 2006: 148-149 y 156-161; Letamendia 1994 vol. I: 349-358; Onaindia 2001: 427-493; Sullivan 1988: 111-134; Uriarte 2005: 115-135; Muñoz 1982: 17.

16 Castro 1998: 70; Uriarte 1997: 218-219; Tusell 1993: 384.
} 
“Sabíamos que era la batalla más decisiva de nuestra vida”, sentenció en sus memorias Mario Onaindia. Él fue el último en hablar. Declarándose "marxista-leninista" e "internacionalista", y haciendo caso omiso de las indicaciones del presidente del tribunal, quiso "aprovechar esta ocasión para exponer la lucha del pueblo vasco y la opresión que sufre. Gora Euskadi Askatuta!” (¡Viva Euskadi Libre!). Según Onaindia, “subí alguno de los escalones del foso hacia el estrado porque temía que en cuanto subiera la voz los 'grises' me cogieran (...). El capitán Troncoso se puso aún más lívido que de costumbre y desenvainó el sable dirigiendo su punta contra mí como si temiera que fuera a abalanzarme contra él".

No obstante, Troncoso revela un detalle esclarecedor: entre los acusados y los miembros del tribunal se situaba la mesa en la que estaban expuestas las pruebas, entre ellas un hacha. Desde su perspectiva, el acusado se estaba acercando demasiado a un arma blanca ${ }^{17}$.

El grito de Onaindia fue la señal para que todos los procesados comenzasen a cantar el Eusko Gudariak (Soldados Vascos), reclamándose así sucesores de los soldados de los batallones abertzales de la Guerra Civil. No obstante, los etarras repitieron una y otra vez la primera estrofa del himno, ya que la siguiente "parecía demasiado folclórica y nacionalista”. Esta perspectiva izquierdista era fruto de su fugaz sintonía con ETA VI ${ }^{18}$.

El 28 de diciembre de 1970 se dictó sentencia. La solicitud de 752 años de cárcel se rebajó a 519 años y seis meses. Sin embargo, las penas de muerte aumentaron de seis a nueve, aunque para las mismas seis personas. Onaindia, Xabier Larena y Unai Dorronsoro recibieron una cada uno. Fueron dos en el caso de Uriarte, Gorostidi y Xabier Izko de la Iglesia. El resto de los encausados recibieron penas de entre 70 y 12 años de prisión, excepto Arantza Arruti, que fue absuelta ${ }^{19}$.

\section{¿Quién estuvo detrás del sumarísimo 31/68?}

Todavía se sigue achacando la paternidad del proceso de Burgos al franquismo en general y al Gobierno en particular. Este análisis retrata a la dictadura como un ente unido y homogeneo. Ahora bien, pese a que la obediencia y la lealtad hacia Franco eran el indiscutible mínimo común denominador, en el interior del régimen siempre hubo

17 "Grabación de las sesiones del juicio a varios miembros de ETA conocido como Proceso de Burgos”, Centro Documental de la Memoria Histórica (CDMH); Onaindia 2001: 487-488; entrevista a Antonio Troncoso, Madrid, 13 y 14 de junio de 2019.

18 Uriarte 2005: 123.

19 "Sentencia de la Causa 31/69", CDMH. 
sensibilidades, intereses y estrategias distintas, tanto a nivel colectivo como individual ${ }^{20}$.

Tras una agria disputa entre el equipo del almirante Luis Carrero Blanco y la familia aperturista de los ministros Fernando María Castiella (Exteriores) y Manuel Fraga Iribarne (Información y Turismo), el 29 de octubre de 1969 Franco sustituyó a 13 de los 18 ministros. El nuevo gabinete, que llevaba el sello del vicepresidente Carrero Blanco y el ministro Laureano López Rodó, estaba compuesto por tecnócratas vinculados al Opus Dei o a la Asociación Católica Nacional de Propagandistas. Franquistas, sin ninguna duda, pero fieles a Carrero Blanco y López Rodo, estaban alejados tanto de las veleidades falangistas de la vieja guardia como del aperturismo de Fraga, que fue sustituido por Alfredo Sánchez Bella. El programa del llamado "Gobierno monocolor" se centraba en el desarrollo económico, el bienestar material de la sociedad y la modernización de España, garantizando siempre la continuidad de la dictadura. Gracias a tales reformas y a unas relaciones cordiales con las potencias occidentales, los tecnócratas esperaban que el país pudiese entrar en la OTAN y la Comunidad Económica Europea ${ }^{21}$.

El sumarísimo 31/69 ponía en serios aprietos los planes de aquel gabinete, que en junio de 1970 había logrado firmar un acuerdo preferencial con el Mercado Común. Nada podía enturbiar más la imagen que deseaba proyectar que la ejecución de seis opositores tras un juicio militar. Desde su perspectiva, tampoco convenía que pudiesen ser utilizados como "mártires" por las fuerzas antifranquistas. Hay que tener en cuenta, además, que la opinión pública española ya no estaba acostumbrada a medidas tan extremas. Si bien habían sido masivos durante la Guerra Civil y la posguerra, no se habían producido ajusticiamientos desde los del comunista Julián Grimau y los anarquistas Joaquín Delgado y Francisco Granado en 1963. A partir de esa fecha todas las condenas a muerte habían sido conmutadas. Por ejemplo, en 1964 la de Andrés Ruiz Márquez (el coronel Montenegro), que había colocado 68 bombas caseras en nombre del Frente Español de Liberación Nacional; en 1968 la de uno de los asesinos de Pardines, Iñaki Sarasketa; y en 1969 la de Andoni Arrizabalaga, que también pertenecía a ETA ${ }^{22}$.

El consejo de guerra no puede achacarse al Gobierno, pero tampoco al franquismo en su conjunto. Tal y como se planteó, causó malestar en otras instancias, ya fuera por haberse unificado todos los sumarios en un solo macroproceso o por el hecho de que se permitiera explayarse a los

\footnotetext{
${ }^{20}$ Molinero e Ysàs 2008.

21 Preston 2002: 806.

22 Cañellas 2015: 404; Sullivan 1988: 112-113; Morán 1982: 73; Palacios 1996: 525.
} 
acusados. En el seno del Ejército también aparecieron voces contrarias a la utilización de consejos de guerra para delitos de terrorismo. En ese sentido se manifestó por carta al capitán general de Burgos el teniente general Rafael García Valiño, quien advertía que las ejecuciones pondrían en peligro la reputación de las Fuerzas Armadas. La misiva fue aireada por la prensa internacional ${ }^{23}$.

De acuerdo con Teo Uriarte, el proceso fue "una operación interna en el seno del régimen", auspiciada por el sector más reaccionario contra el de los tecnócratas. Coincide aquí con Gregorio Morán, para quien “el sumario se había preparado bajo las órdenes del capitán general de la VI Región Militar”, Manuel Cabanas Vallés, que en junio de 1970 fue sustituido por Tomás García Rebull. Habría que sumar, según Morán, al capitán Troncoso y al coronel auditor Fernando Suárez de la Dehesa, "el auténtico cerebro gris" del consejo de guerra. Por consiguiente, "el Gobierno vivió a la defensiva el Proceso de Burgos. Estaba a expensas de las decisiones de los responsables del juicio y estos sabían muy bien en qué consistía su fuerza"24.

El comisario José Sainz, pieza clave en la desarticulación de ETA en 1969, también creía que el origen del sumarísimo 31/69 era la Capitanía General de Burgos. Ahora bien, más que intencionalidad política, él veía simple dejadez. La tramitación de la causa se había demorado dos años, cuando podría haberse resuelto mucho antes, por culpa de "la propia Institución Militar", que había "vivido de espaldas" a la amenaza de ETA. La Auditoría de Guerra tardó ese tiempo en "estudiar y comprender" el problema $^{25}$.

Juan Mari Bandrés estaba convencido de que el consejo de guerra llevaba la firma de la Capitanía General de la VI Región Militar, pero apuntaba directamente al capitán Troncoso, que "se creyó 1lamado por la voz divina a ser el gran revelador de ETA, el gran inquisidor del pueblo vasco y entonces empezó a agrupar un gran proceso que podía ser la causa general del pueblo vasco". No había que pensar en nada complejo. Fue "simplemente algo mucho más elemental, es decir, un auditor que dice ésta es la mía" sin tener en cuenta las repercusiones ${ }^{26}$.

Si bien Troncoso tuvo un papel crucial en el proceso, Bandrés olvidaba que el auditor era el coronel Suárez de la Dehesa. Uno no podría haber actuado sin el otro. ¿Y el capitán general de Burgos? Troncoso opina que García Rebull “venía para apaciguar, para minimizar el tema”. Tanto es así

${ }^{23}$ Delgado 2005: 262; Rodríguez 1994: 136; Sullivan 1988: 130; la carta y su eco en prensa, Fundación Nacional Francisco Franco (FNFF).

${ }^{24}$ Uriarte 2013: 69; Morán 1982: 71 y 72.

25 Sainz 1993: 242.

26 Castro 1998: 59; Morán 1982: 71.

Araucaria. Revista Iberoamericana de Filosofia, Política, Humanidades y Relaciones Internacionales, año $22, \mathrm{n}^{\circ} 44$. Segundo semestre de 2020. Pp. 27-51. ISSN 1575-6823 e-ISSN 2340-2199 https://dx.doi.org/10.12795/araucaria.2020.i44.02 
que intentó que el vocal ponente descartase el informe balístico sobre la pistola del acusado de haber asesinado a Manzanas, Izko de la Iglesia, a lo que se negó. El capitán general no fue, por tanto, uno de los promotores del sumarísimo 31/69. Ahora bien, ¿de verdad la paternidad le correspondía a alguien? Una vez arrestados, había que juzgar a los líderes de ETA. Según el Decreto-ley 9/1968, de 16 de agosto, sobre represión del bandidaje y terrorismo, que había promulgado el Gobierno anterior, tenía que ser ante un tribunal militar. Y, debido a la negativa de los sacerdotes detenidos y sus prelados, debía hacerse en audiencia pública. Apenas había margen de maniobra en dichos aspectos ${ }^{27}$.

A la Auditoría de Guerra sí se le puede achacar la unificación de todos los sumarios abiertos a líderes de ETA en un solo macroproceso, lo que facilitó su instrumentalización mediática por los encausados. ¿Por qué se hizo así? Creemos que hubo varios motivos. Por un lado, siguiendo el principio de economía procesal, era habitual que la jurisdicción militar agrupase las causas sobre delitos idénticos. La norma tenía todo el sentido si se toma en consideración, como resaltaba un informe del Ministerio del Ejército, "la extraordinaria complejidad del enjuiciamiento" a los dirigentes etarras: en los procedimientos coincidían muchos acusados, pruebas y testimonios. Además, con anterioridad el coronel auditor había encomendado todos los sumarios sobre ETA al capitán Troncoso, con lo que era natural que él los tratase como si fuesen uno solo. Por último, hay indicios de que la Auditoría de Guerra se planteaba un juicio ejemplarizante que disuadiese de seguir con la violencia a lo que quedaba de ETA. Desde luego, el tiro le salió por la culata ${ }^{28}$.

\section{Historia de un soborno}

Aclarado el origen del sumarísimo 31/69, debemos poner la lupa sobre una operación con la que se pretendió atenuar la mala publicidad que iba a generar. La llevó a cabo un alto cargo del Gobierno de manera ilegal. El intento de soborno acabó en un fiasco, causó serias fricciones en el seno del régimen y puso en peligro dos carreras políticas. Se abrió una instrucción judicial, aunque no trascendió a la prensa y tampoco ha sido recogida por la historiografía académica. Sí mencionan la tentativa autores como Ricardo de la Cierva y Gregorio Morán, que daban la historia por cierta, aunque otros la tachan de simples "rumores". Sin embargo, fue

\footnotetext{
27 Entrevista a Antonio Troncoso, cit.

28 "Informe sobre las actividades separatistas en las provincias vasco-navarras", San Sebastián, 10-9-1969, FNFF; entrevista a Antonio Troncoso, cit.
} 
real $^{29}$.

El sospechoso de mayor rango fue el ministro de Información y Turismo Alfredo Sánchez Bella. Hermano del consiliario del Opus Dei en España, pero ligado a la Asociación Católica Nacional de Propagandistas, antes había sido director del Instituto de Cultura Hispánica (1948-1956), así como embajador en la República Dominicana (1957-1959), Colombia (1959-1962) e Italia (1962-1969) ${ }^{30}$.

Gracias a Andrés Zaragoza, sabemos que durante el consejo de guerra el Ministerio de Información y Turismo “desempeñó una labor destacada para conseguir que la información que facilitaron los medios de comunicación nacionales fuese la 'adecuada', mientras que se intentaban matizar las noticias ofrecidas por los medios extranjeros". Incluso existió un "anteproyecto de campaña de actuación sobre el asunto Operación Burgos", que Tusell califica como "un modelo de incompetencia". En el texto se ordenaba que "todos nuestros Consejeros, Agregados y, donde sean utilizables, los Directores de Oficinas de Turismo, deberán realizar una campaña de contacto personal con los medios, prometiendo o amenazando, según los casos, pero buscando en todo momento la colaboración, la abstención o la neutralidad informativa sobre el tema". Aunque el anteproyecto no especificaba qué clase de promesas o amenazas debían hacer los funcionarios, parece sugerir que el Ministerio estaba dispuesto a saltarse ciertos límites ${ }^{31}$.

Con todo, resulta imposible saber si el intento de soborno estaba relacionado con este plan y hasta qué punto estuvo implicado Sánchez Bella, si es que lo estuvo. La única certeza es que Mariano Rojas García se presentaba como su agente. Se trataba de un periodista que había hecho carrera como alto funcionario del Ministerio de Información y Turismo: era el subjefe de los Servicios Informativos de la Dirección General de Prensa, que según uno de sus antiguos redactores era "un gabinete de prensa del Gobierno con un servicio interior para el ministro y los altos cargos, y otro exterior funcionando como una agencia de prensa" ${ }^{\prime 2}$.

Troncoso recuerda que, poco antes del inicio del proceso, Rojas comió con él y su mujer en un hotel de Burgos. Cuando estaban tomando el café, el periodista le dijo que tenía un encargo "muy desagradable" de "mi ministro", aunque el capitán sospechaba que quien estaba realmente detrás era el Gobierno o el vicepresidente Carrero Blanco. "Si el consejo de guerra no pone pena de muerte ninguna, te ofrecen que tú te vienes a

29 Morán 1982: 71-72; Jáuregui y Vega 1984: 383-384; San Martín 1983: 36; Cierva 1978: 337-338.

${ }^{30}$ Cañellas: 2015.

31 Zaragoza 1993; Tusell 1993: 384

32 Chuliá 1997: 379.

Araucaria. Revista Iberoamericana de Filosofía, Política, Humanidades y Relaciones Internacionales, año 22, $\mathrm{n}^{\circ} 44$. Segundo semestre de 2020. Pp. 27-51. ISSN 1575-6823 e-ISSN 2340-2199 https://dx.doi.org/10.12795/araucaria.2020.i44.02 
Madrid de vicepresidente" del Banco Hipotecario, el Banco de Crédito Agrícola o el Banco de Crédito a la Construcción. Suponía pasar de un sueldo mensual de 16.000 pesetas a otro de 200.000 , pero la respuesta de Troncoso fue negativa. "Las penas que se pongan han de ser serias, dada la gravedad de los hechos". Inmediatamente el capitán informó al coronel Suárez de la Dehesa, pidiéndole que el intento de soborno quedase entre los dos. "Ya se ve cómo está el ambiente", dijo Troncoso. "Si no quieren que nosotros intervengamos, hay una fácil solución": que el fiscal togado ordenase al fiscal de Burgos que se inhibiera, que este lo plantease, que el auditor accediera, que el capitán general "se moje el culo" y que se mandase el sumarísimo al Tribunal del Orden Público. "Pero mientras venga a la jurisdicción y esté en consejo de guerra", advirtió Troncoso, "yo voy a aplicar la ley"33.

El episodio retrasó el comienzo de la audiencia, pero no tendría por qué haber tenido consecuencias. Sin embargo, unos días después Rojas comentó la oferta que le había hecho al vocal ponente delante de otras personas, incluyendo el coronel Suárez de la Dehesa. Estaba "asombrado del rigor y la independencia" del tribunal militar, que era capaz de resistir las presiones gubernamentales. Lo que pretendía ser un halago acabó creándole un grave problema al periodista. El 10 de febrero de 1971 la Auditoría de Guerra abrió el sumario 18/71 contra Mariano Rojas por un "presunto delito de intento de soborno", pidiendo una "pena de un mes y un día de arresto mayor con sus accesorias legales y multa de cinco mil pesetas".

El Ministerio Fiscal no dudó en acusar al ministro Sánchez Bella de ser el inspirador de aquella operación. Por tanto, el sumario fue remitido al Consejo Supremo de Justicia Militar, el único órgano competente para encausar a una autoridad de tal nivel. El tribunal declinó su idoneidad, ya que en aquel momento la investigación no había confirmado "suficientemente los motivos y circunstancias que inspiraron la actuación" de Mariano Rojas.

No obstante, fue suficiente para que en marzo se remitiese a Franco un informe de siete páginas sobre el ministro de Información y Turismo, que incluía notas del Servicio de Seguridad e Información de su Casa Militar y del secretario de coordinación del Movimiento. El documento no solo ponía en tela de juicio la actuación de Sánchez Bella durante la Guerra Civil ("un importante cargo en zona roja"), sino también su fidelidad al régimen y al propio "Caudillo", contra el que habría proferido "palabras injuriosas". Entre otras cosas se le acusaba de haber escrito una carta en 1963 "condenando severamente la ejecución de Grimau y diciendo que este

33 Sumario 18/71, Archivo Intermedio Militar Noroeste y JTMT; entrevista a Antonio Troncoso, cit. 
asunto impedirá la admisión de España entre las Naciones Occidentales de Europa"34.

Durante el periodo procesal se recabó el testimonio de "todas las personas intervinientes en las conversaciones reveladoras del supuesto delito perseguido, incluso el del titular del Departamento de Información y Turismo", ya que contra él existía "indicio de culpabilidad". El capitán Troncoso, el coronel Suárez de la Dehesa y otro oficial, "todos ellos personas dignas del mayor crédito", declararon que Rojas había ofrecido un soborno en nombre del ministro de Información y Turismo. Ahora bien, tanto el periodista como el propio Sánchez Bella negaron que Rojas hubiese estado siguiendo sus órdenes. A decir de Rojas, "si otra cosa manifestó ante los testigos fue por su propia cuenta, excediéndose en sus atribuciones". Aquello bastó para que la supuesta culpabilidad de Sánchez Bella no pudiese mantenerse "racionalmente". En palabras del auditor, "es perfectamente compatible que el Señor Rojas hiciese las manifestaciones denunciadas, tal y como las presentan los testigos, y sin embargo no fuesen ciertas".

Aún así, el Ministerio Fiscal alegó que el sumario estaba incompleto y que, "no habiéndose desvanecido los indicios de culpabilidad contra el titular del Departamento de Información y Turismo", la jurisdicción de Burgos era incompetente. Los autos debían ser transferidos al Consejo Supremo de Justicia Militar. No obstante, la petición fue denegada por el auditor.

El consejo de guerra contra Mariano Rojas no llegó a celebrarse. E1 23 de septiembre de 1971, con motivo del "XXXV Aniversario de la exaltación a la Jefatura del Estado", el Gobierno decretó un indulto que benefició tanto a los condenados por el escándalo Matesa como a personas que estaban siendo procesadas o estaban ya encarceladas ${ }^{35}$. Una de ellas fue Mariano Rojas. El 29 de diciembre de aquel mismo año se sobreseyó el sumario 18/71, que sería archivado el 18 de febrero de 1972.

El 18 de julio de 1972, tan solo cinco meses después del archivo de la causa, el Ministerio de Relaciones Sindicales concedió a Mariano Rojas la distinción al Mérito Sindical en su categoría de Medalla de Plata. La historia tiene otra coda. Tras la remodelación del Gobierno de 1973, Sánchez Bella fue nombrado presidente del Banco Hipotecario, puesto en el que permanecería hasta $1978^{36}$.

\footnotetext{
34 "Notas informativas de los Servicios de Seguridad de la Presidencia del Gobierno sobre Alfredo Sánchez Bella", III-1971, FNFF.

35 BOE, 1-10-1971.

36 Boletín de la Organización Sindical, 1-8-1972; Cañellas 2015.
} 


\section{Historia de un indulto}

El intento de soborno no fue la única maniobra para suavizar la sentencia del proceso de Burgos. Otra estuvo auspiciada por el capitán Andrés Cassinello, que formaba parte de los servicios secretos, la Organización Contrasubversiva Nacional (OCN) del coronel José Ignacio San Martín, precedente del Servicio Central de Documentación de la presidencia del Gobierno (SECED).

"Un día, una de las estudiantes con la que contactaba, me planteó su problema: ella era amiga del hermano de uno de los condenados, Izco de la Iglesia, y me pregunta si yo estaba dispuesto a canalizar una petición de clemencia", relata Cassinello en sus memorias. "Le dije que sí, entré en contacto con el interesado y recogí su patética petición de gracia". De todos los imputados, Xabier Izko de la Iglesia era el que peor lo tenía. Estaba acusado de ser el autor material del asesinato del inspector Manzanas, delito por el que sería condenado a dos penas de muerte. Pese a que siempre negó su participación en el atentado, había pruebas en su contra. Por un lado, el sospechoso había sido reconocido tanto por la viuda como por la hija de la víctima. Por otro, Izko de la Iglesia portaba el arma del crimen cuando fue detenido en enero de $1969^{37}$.

Pese a todo, Cassinello le presentó la petición al coronel San Martín, que "la acogió favorablemente y quien nos abrió paso a [Antonio María de] Oriol, entonces Ministro de Justicia. La primera entrevista con él, a la que asistimos el hermano de Izco y yo, fue extremadamente cordial y esperanzadora". El vizcaíno Oriol y alguno de los altos cargos del Ministerio eran carlistas, como la familia de Izko, lo que facilitó la "aproximación psicológica y un camino abierto a la esperanza" ${ }^{38}$.

Las memorias de Cassinello incluyen copia de la petición de clemencia para Franco que firmaron la madre y la hermana del miembro de ETA. Se exponía que "somos una familia humilde española" y se subrayaba la "sincera y firme adhesión que a lo largo de nuestra vida hemos manifestado hacia su Excelencia y hacia los valores que su persona representa en nuestra Patria". También se recordaba que el padre del acusado, Jesús Izco Anocibar, había luchado "como voluntario en la cruzada, en un Tercio de Requetés de Navarra" y había sido herido en campaña. El hecho de que el hijo de un excombatiente carlista se hubiera integrado en ETA da a entender hasta qué punto una capa de la sociedad vasca y navarra se había distanciado del franquismo ${ }^{39}$.

\footnotetext{
${ }^{37}$ Cassinello: 21; Sumarísimo 31/69, 1970, AJTCM.

38 Cassinello: 21.

39 Cassinello: 22.
} 
El 30 de diciembre de 1970, durante el Consejo de ministros en el que se trató acerca de la posible conmutación de las condenas a muerte, Antonio María de Oriol leyó la carta de la familia de Izko de la Iglesia. Cassinello consideraba que aquella petición había sido un factor crucial, pero resulta imposible calcular qué peso específico tuvo en la decisión final de Franco. Hay que tener en cuenta que en el dictador confluyeron influencias de muy distinto signo ${ }^{40}$.

Las fuerzas antifranquistas orquestaron una campaña de movilizaciones contra las ejecuciones. Los paros, las huelgas y las marchas se sucedieron en Euskadi. El 4 de diciembre los disparos de las FOP hirieron a un joven trabajador militante del PCE (internacional), Roberto Pérez Jauregui, que estaba manifestándose en Éibar. Falleció cuatro días después. También hubo movilizaciones en el resto de España, así como en puntos de Europa occidental y Latinoamérica. De acuerdo con Garmendia, todas ellas "tenían un carácter antirrepresivo, sin distinciones políticas e ideológicas: se trataba de salvar la vida de seis jóvenes que podían ser víctimas del régimen". En consecuencia, indica Patxo Unzueta, el proceso de Burgos "se convirtió, especialmente para la juventud, en el símbolo vivo del antifranquismo". El efecto fue aún mayor en el ambiente nacionalista vasco ${ }^{41}$.

El 4 de diciembre de 1970 el Gobierno declaró un estado de excepción en Guipúzcoa, que luego se extendió al conjunto de España. Hasta el 12 de abril de 1971 hubo 1.221 arrestos. Pese a aquella medida, las autoridades franquistas parecían a punto de ser desbordadas. El gobernador civil de Guipúzcoa Julio Iranzo Domínguez admitió que

las alteraciones, incidentes y actuaciones subversivas de los últimos meses de 1970 y comienzo de 1971 han sido, sin duda alguna, más violentos y más graves en número e importancia que las de los años precedentes, pudiendo afirmarse que, desde la Guerra de Liberación, no se había creado una situación tan difícil y preocupante ${ }^{42}$.

También hubo quien dentro del régimen abogó por la conmutación de las penas máximas. Por ejemplo, Nicolás Franco, el hermano mayor del "Caudillo", que le pedía por escrito: "no firmes esas sentencias. No te conviene. Te lo digo porque te quiero. Tú eres un buen cristiano, después te arrepentirás. Ya estamos viejos". Lo mismo hicieron bastantes gobiernos occidentales, la Conferencia Episcopal Española y el papa Pablo VI. Incluso hubo peticiones de clemencia en la prensa española. Hasta entonces se había dejado guiar por el Ministerio de Información y Turismo, por lo

${ }^{40}$ Tusell 1993: 385-386.

${ }^{41}$ Garmendia 2006: 157; Unzueta 1988: 91.

${ }^{42}$ Casanellas 2014: 83-90; "Memoria de la provincia correspondiente al año 1970", 1971, Archivo Histórico Provincial de Gipuzkoa (AHPG), c. 3676/0/1.

Araucaria. Revista Iberoamericana de Filosofia, Politica, Humanidades y Relaciones Internacionales, año $22, \mathrm{n}^{\circ} 44$. Segundo semestre de 2020. Pp. 27-51. ISSN 1575-6823 e-ISSN 2340-2199 https://dx.doi.org/10.12795/araucaria.2020.i44.02 
que Uriarte entiende que también lo estaba haciendo en este asunto. $\mathrm{Su}$ finalidad sería preparar a la opinión pública para el indulto ${ }^{43}$.

Era necesario, porque un considerable sector del régimen abogaba abiertamente por la mano dura. Un documento que el ministro Sánchez Bella remitió a Franco el 1 de diciembre de 1970 avisaba de que muchos militares anhelaban un castigo ejemplarizante. Exactamente lo mismo ocurría en las FOP. José Sainz, entonces jefe superior de Policía de Bilbao, cuenta que "en algunas dependencias policiales de otras provincias se habían producido conatos de protesta contra cualquier postura indulgente que se produjera". También "un reducido número" de los agentes bajo su mando "pretendía hacer campaña en tal sentido, por lo que me apresuré a reunirlos y hablarles a todos". No convenció a la minoría más exaltada, pero desistieron de sus propósitos. La actitud de Sainz fue elogiada por el director general de Seguridad en su discurso de Nochevieja resaltando los valores de la lealtad, la obediencia y el deber ${ }^{44}$.

El descontento también se hizo visible en la calle. El 16 de diciembre hubo una nutrida concentración en Burgos, de 40.000 personas según $L a$ Actualidad, y al día siguiente se produjo una masiva manifestación en la Plaza de Oriente de Madrid. La prensa nacional contó 500.000 asistentes, pero, midiendo el espacio que ocuparon, Cassinello calculaba que no fueron más de 300.000. Contra lo que se dijo, no fue espontánea, sino que había sido organizada por la OCN de San Martín, que ni siquiera había consultado con el Gobierno. Según recordaba el coronel, cinco equipos desde vehículos y otros cuatro en el metro repartieron 500.000 panfletos. Como el acto no fue autorizado hasta el día 16, algunos de los colaboradores del servicio de inteligencia fueron arrestados por las FOP, "si bien fueron puestos en libertad inmediatamente". Carrero aceptó el proyecto, pero no así el ministro de Gobernación, el navarro Tomás Garicano Goñi, "que estaba realmente asustado de aquello que consideraba como una locura" 45 .

Tenía sus razones. La concentración no solo buscaba mostrar la adhesión popular al dictador y al Ejército, sino que también sirvió para canalizar el rechazo al Gobierno, contra el que iban dirigidos ciertos lemas y pancartas. Resulta sintomático que, al terminar el acto, el médico de cabecera de Franco, Vicente Gil, camisa vieja y enemigo declarado del Opus Dei, tuviese un altercado público con Sánchez Bella, al que llamó "inepto" y al que reprochó su "mano blanda". "Eres un gallo "capao"”. El mensaje estaba claro y la demostración de fuerza ultra había sido un éxito. Se trató de uno de los actos de masas más concurridos del franquismo ${ }^{46}$.

\footnotetext{
${ }^{43}$ Preston 2002: 812; Uriarte 2013: 78.

44 Cañellas 2015: 404-405; Sainz 1993: 243.

45 Rodríguez 1994: 137-139; San Martín 1983: 36-37; Cassinello; La Actualidad, 24-12-1970.

46 ABC, 18-12-1970; Cassinello: 23-24; Muñoz 1982: 19; Preston 2002: 813; Gil 1981: 100-103.
} 
Pese a aquellas presiones, los dos hombres fuertes del Gobierno, López Rodo y Carrero Blanco, estaban a favor de que Franco ejerciese el derecho de gracia. Ambos se vieron el día 29 de diciembre a última hora de la tarde. Según el ministro, el vicepresidente argumentó que "pedir que se ejecuten las penas de muerte sería caer en una trampa. Porque, ¿qué es lo que pretende el adversario? Que se cumplan las penas capitales para 'hacer mártires'. Entonces, ¿qué debemos hacer nosotros? Pedir el indulto". Por otra parte, el propio López Rodo habría añadido que las ejecuciones eran un "error político" y podían "ensombrecer la imagen de Franco ante la Historia y ante el mundo". Hay que recalcar esto último: había que evitar una publicidad negativa para la imagen que el Gobierno pretendía proyectar a escala internacional. De acuerdo con Javier Tusell, "lo más probable es que el conocimiento de su postura se transmitiera al resto del Consejo de ministros". Por consiguiente, durante la reunión, a la que asistió Franco, el apoyo al perdón fue mayoritario. A decir del ministro de Trabajo, Licinio de la Fuente, tras escucharles el dictador les dijo: "Muchas gracias, no saben ustedes el peso que me han quitado de encima". Se conserva un borrador del acta de aquel consejo, que el propio Carrero modificó y simplificó luego para "ratificar la unanimidad de la decisión", pese a que diversas fuentes indican que hubo voces discrepantes. En todo caso, la conmutación de las condenas a muerte ya había recibido el respaldo del Consejo del Reino, donde fue defendida por el general Manuel Díez-Alegría, jefe del Alto Estado Mayor ${ }^{47}$.

\section{Las grietas del régimen}

El 30 de diciembre de 1970 el "Caudillo" indultó a los etarras condenados a muerte. Aquel decreto fue contemplado como una victoria por ETA V, que lo achacó al secuestro del cónsul alemán y a las movilizaciones contra las ejecuciones. Dentro del régimen el perdón de Franco provocó respuestas divergentes. En la memoria del Gobierno Civil de Guipúzcoa se podía leer que "originó de momento algunas diferencias de opinión, entre los que deseaban una política de firmeza que atacara los peligrosos brotes del proceso subversivo frente a otra opinión generalizada que estima la prudencia de la medida de conmutación"

Para el Gobierno, que lo publicitó como una muestra de su fortaleza, el indulto era una forma de cerrar la "crisis de diciembre". No estaba solo. Desde

\footnotetext{
${ }^{47}$ Martín García 2009: 114; López Rodo 1979: 534; Fuente 1998: 149-150; Zaragoza 1993; Tusell 1993: 382-386.

${ }^{48}$ Hordago 1979: 237-238; Muñoz 1982: 20; Rodríguez 1994: 135-147; "Memoria de la provincia correspondiente al año 1970", 1971, AHPG, c. 3676/0/1.
}

Araucaria. Revista Iberoamericana de Filosofia, Politica, Humanidades y Relaciones Internacionales, año $22, \mathrm{n}^{\circ} 44$. Segundo semestre de 2020. Pp. 27-51. ISSN 1575-6823 e-ISSN 2340-2199 https://dx.doi.org/10.12795/araucaria.2020.i44.02 
la perspectiva de muchos funcionarios, suponía el fin de las tensiones y la incertidumbre. Juan Mari Bandrés recordaba que, justo al poco de conocerse la noticia, la Guardia Civil le paró en Burgos. "Yo creo que se alegraban...". Los mismos agentes "sintieron una especie de alivio al pensar que no había que ejecutar esas penas, por lo menos yo percibí muy claramente eso en aquel control" 49 .

El indulto también fue bien recibido por determinadas autoridades provinciales. El Gobierno Civil de Guipúzcoa reconocía que "transcurrieron los primeros meses del año [1971] en una calma generalizada, que disiente completamente de las reacciones y tensiones en que finalizó 1970". Desde su perspectiva, además, el uso del derecho de gracia por parte del "Caudillo" había hurtado a ETA "un arma de explotación propagandística al elevar a la categoría de mártires a los terroristas condenados durante el citado proceso" ${ }^{50}$.

Pero el sector moderado era consciente de que la calma no iba a durar. Siguiendo a Paul Preston, a raíz del proceso "los franquistas más aperturistas comenzaban a abandonar lo que veían como un barco que se estaba hundiendo". En realidad, algunos llevaban un tiempo haciéndolo. Un informe de la Embajada de Gran Bretaña indicaba que altos cargos como el general Díez-Alegría "estaban intentando distanciarse de los acontecimientos diarios relacionados con los juicios de Burgos" para "preservar su influencia y prestigio para ocasiones futuras". Es más, dicho militar ya se había reunido con representantes de la oposición antifranquista catalana, a los que, según los periodistas Fernando Jáuregui y Pedro Vega, les dijo que el sumarísimo 31/69 “enconaría mucho más la situación, haría todavía más difícil la salida a la democracia y que perjudicaría enormemente la imagen del Ejército de cara al futuro y le hipotecaría ante el pueblo español"51.

En sus memorias, el primo y colaborador del dictador, el general Francisco Franco Salgado-Araújo, reflejaba que a principios de 1971 "había gran efervescencia en los medios semioficiales contra el gobierno, compuesto en su mayoría por miembros del Opus Dei". En efecto, López Rodo dejó escrito que "el proceso de Burgos también fue extremadamente cotizado por diversas esferas y personas para tratar de hacer caer al Gobierno". Se refería a la facción más reaccionaria del régimen, que en 1969 ya se había indignado por la designación del príncipe Juan Carlos como heredero de la Jefatura del Estado y por la formación del "Gobierno monocolor". En opinión de José Luis Rodríguez Jiménez, el sumarísimo 31/69 "puede ser considerado como el punto de arranque para el aglutinamiento de una parte de los distintos componentes de la extrema derecha española”. Este sector interpretó el desenlace del juicio

\footnotetext{
49 Molinero e Ysàs 2008: 144; Castro 1998: 73.

50 "Memoria de la provincia correspondiente al año 1970", 1971, AHPG, c. 3676/0/1.

51 Preston 2002: 813-814; Martín García 2009: 114; Jáuregui y Vega 1984: 381-382.
} 
como una evidencia más de la paulatina debilidad de la dictadura y del propio Franco, "manejado" por los tecnócratas. Comenzaba a decantarse lo que más adelante sería conocido como el "Bunker"52

A una parte sustantiva del Ejército le irritaron los discursos de los procesados en Burgos, que se utilizara un tribunal militar para juzgar delitos de terrorismo y, sobre todo, el indulto. Los oficiales no hicieron responsable a su "Caudillo", sino al Gobierno. Según documentación de la CIA, a mediados de diciembre de 1970 un general destinado a Canarias había hecho "un evidente aviso al Opus Dei" al declarar que "todos deben saber que estamos preparados para tomar las armas, aunque comprendemos que debemos actuar sólo como último recurso". En enero de 1971 el capitán general de la IX Región Militar (Granada), Fernando Rodrigo Cifuentes, también pronunció un duro discurso contra el Opus Dei, por el que tan solo unos días después sería destituido de su cargo. En diferentes puntos hubo reuniones de oficiales en las que, con la excusa del sumarísimo 31/69, acabaron vertiéndose quejas sobre la situación general del Ejército y la hegemonía de los tecnócratas. Circularon memoriales de agravios y el propio Franco recibió alguna carta en ese sentido ${ }^{53}$.

"El malestar era general", recuerda Troncoso, "pero más en Burgos". El capitán, que se había tomado un tiempo de descanso, iba con su mujer de camino a Madrid cuando le paró la Guardia Civil. Tenía que volver a Burgos inmediatamente. Allí el capitán general García Rebull le informó de que estaban "los ánimos exaltados" por la conmutación de las penas y le ordenó "apaciguarlos" justificando la decisión de Franco en todos los cuarteles de la guarnición. En sus visitas Troncoso se enteró de que habían ocurrido incidentes que él define como "sedición" e "insubordinación". Por ejemplo, en la sala de banderas del Regimiento España de Caballería, García Rebull habría advertido a los militares que cuando un mando se enfrentaba a la deslealtad de sus inferiores "lo mejor era pegarse un tiro". Un capitán se habría dirigido al oficial de guardia: "teniente, haga usted el favor de cederle la pistola al capitán general" 54 .

El coronel San Martín destacaba la contribución de los servicios secretos para "serenar los ánimos", pero no fue suficiente. Para Sullivan, "el anuncio de que se iban a conceder aumentos de sueldo a las fuerzas armadas fue, posiblemente, una respuesta al descontento del ejército". Según Andrés Zaragoza, también contribuyeron ciertos ascensos, como el

\footnotetext{
52 Franco 1976: 559; López Rodo 1979: 534; Rodríguez 1994: 135-147; Casanellas 2014: 96; Molinero e Ysàs 2008: 142-163.

53 Delgado 2005: 263-264; Cardona 1990: 199; Casanellas 2014: 96-97; Rodríguez 1994: 143-146; Sullivan 1988: 130; Martín García 2009: 114; Zaragoza 1993; "Directorate of Intelligence, Weekly Summary, Secret”, no 0354/71, 22-1-1971, sig. CIA-RDP79-00927A008500030001-7, documento cedido por David Mota.

${ }^{54}$ Entrevista a Antonio Troncoso, cit.
} 
de García Rebull, que en febrero de 1971 fue nombrado capitán general de la I Región Militar ${ }^{55}$.

\section{Conclusiones}

En 1970 ETA estaba desorientada y dividida en dos. La batalla por las siglas la ganó ETA V, que se nutrió de la publicidad internacional generada alrededor del sumarísimo 31/69 y del secuestro del cónsul de la RFA, así como del cuantioso aporte de militantes de EGI-Batasuna. Su recuperación permitió a la banda impulsar una nueva campaña de atentados terroristas. Causó una víctima mortal en 1972, seis en 1973, diecinueve en 1974 y catorce en 1975. Debido al capital simbólico-político acumulado durante el proceso de Burgos y la brutal represión posterior, una parte de la ciudadanía vasca vio en la organización a una especie de "Mesías" armado. Mientras tanto las víctimas del terrorismo eran identificadas con el régimen. Aquella inercia perduró en algunos ámbitos mucho más allá de la muerte de Franco ${ }^{56}$.

ETA obtuvo réditos del consejo de guerra gracias a la actuación de los imputados, divulgada por los medios de comunicación, la campaña de propaganda orquestada por el nacionalismo radical y las movilizaciones auspiciadas por otras fuerzas, cuya finalidad era salvar seis vidas, pero que la organización reinterpretaría como un apoyo a su causa. Pero aquel fenómeno hubiera sido imposible sin las discrepancias que se registraban en el seno del régimen, la draconiana legislación que hacía competente a los tribunales militares para juzgar delitos de terrorismo, la decisión de la Audiencia de Guerra de unificar los sumarios en un macroproceso, los errores del Ministerio de Información y Turismo y la libertad con la que la prensa internacional accedió tanto a la audiencia pública como a los abogados defensores. El resultado fue que los encausados fueron elevados a la categoría de héroes. Siguiendo sus pasos, cientos de jóvenes se integraron en ETA o los organismos sectoriales que irían surgiendo a su alrededor. A la hora de ser juzgados, muchos miembros de la banda terrorista imitarían la actitud de Mario Onaindia y sus compañeros ${ }^{57}$.

La literatura militante de corte nacionalista radical todavía mantiene que el proceso de Burgos fue orquestado por el régimen para dar un "escarmiento" al "pueblo vasco". No es cierto. En primer lugar, como

\footnotetext{
55 San Martín 1983: 36; Sullivan 1988: 130; Zaragoza 1993.

${ }^{56}$ Fernández y Domínguez 2018; Garmendia 2006: 152-166.

57 Domínguez 1998: 30; Garmendia 2006: 155; Jáuregui 2006: 258; Pablo 2015: 380.
} 
es evidente, ETA jamás ha representado a la sociedad vasca. Segundo, el Gobierno franquista no fue el impulsor del sumarísimo 31/69 y las penas de muerte, sino justo lo contrario. Tercero, desde la promulgación del Decretoley sobre represión del bandidaje y terrorismo en 1968, los acusados por delitos de terrorismo eran juzgados ante un tribunal militar. Cuarto, la agrupación de las causas abiertas fue decisión de la Auditoría de Guerra de la VI Región Militar, que funcionaba con autonomía. La unificación era habitual en esta esfera, pero es más que probable que también se buscase un juicio ejemplarizante para acabar con los atentados de ETA.

Aunque no se adscribía a ninguna familia concreta, el vocal ponente del proceso de Burgos, el capitán Troncoso, era franquista; al igual que la absoluta mayoría de los oficiales del Ejército. No obstante, si solo hiciésemos hincapié en ese factor, pasaríamos por alto que tanto él como otros miembros de la Auditoría de Guerra también se caracterizaban por una forma tradicional de la fe católica, su particular código del honor y su apego férreo a la justicia militar. En palabras del propio Troncoso, su deber era "aplicar el rigor de la ley". Solo teniendo en cuenta dicho principio podemos comprender sus decisiones y por qué no dudó en seguir adelante con las condenas a muerte, que creía un castigo justo, pese a las presiones del capitán general García Rebull, el riesgo para su futuro profesional, el tentador soborno y el hecho de estar poniendo en aprietos al Gobierno y, por ende, a la estabilidad del régimen. Dura lex, sed lex.

Los esfuerzos de los tecnócratas por blanquear la imagen de la dictadura se vieron perjudicados por el sumarísimo 31/69. Que un tribunal militar sentenciase a muerte a quienes eran vistos como opositores antifranquistas escandalizó, con razón, a gran parte de la prensa y la opinión pública internacional. Por añadidura, las movilizaciones contra las ejecuciones dentro de España fueron un indicio del paulatino crecimiento de la oposición, que el régimen solo fue capaz de controlar mediante la represión policial y el recurso al estado de excepción.

Las disensiones internas no eran una novedad en la dictadura, pero el consejo de guerra las exacerbó. Por un lado, la Iglesia católica empezaba a darle la espalda. Lo mismo hacía una porción de los hijos de los vencedores de la Guerra Civil. Por otro lado, algunos militares acumulaban agravios y expresaban su descontento en público. Por último, con un "Caudillo" cada vez más avejentado, se acentuó la división entre las familias franquistas: aperturistas, tecnócratas, reaccionarios... La extrema derecha se movilizó, con hitos como la manifestación de la Plaza de Oriente, pero no logró derribar al Gobierno. Según un informe que Cassinello redactó en febrero de 1971, como no habían desalojado a los tecnócratas, los ultras "ven 
disminuida su fe en el sistema político establecido. A la larga, la situación va evolucionando en deterioro del Régimen", que no ofrecía "una vía institucionalizada por la que canalizar su desacuerdo" 58 .

La gestión gubernamental del proceso de Burgos fue ineficaz. De todos los fiascos que acumuló el Consejo de ministros, el más peligroso para el proyecto tecnócrata fue la tentativa de cohecho, que pudo haber causado un gran escándalo. Que se instruyese un sumario en el que se pretendía implicar al ministro de Información y Turismo es una prueba de la independencia de la Auditoria de Guerra. No tenemos la certeza de que Mariano Rojas estuviese siguiendo las órdenes del ministro Sánchez Bella, pero resulta difícil creer que actuase por su cuenta. No es descartable, sin embargo, que la iniciativa hubiese partido de otro alto cargo del Ministerio o de otro departamento del Gobierno.

La historia del intento de soborno fue una de las grietas que habían aparecido en el régimen. No se trataba de un ente homogéneo y unido, sino que contenía fuerzas centrífugas en su seno. Todos los franquistas eran leales al "Caudillo", pero aquella fidelidad no iba a sobrevivirle. Algunos dudaban de que la dictadura pudiese perpetuarse; otros lo deseaban a toda costa. Todos se preguntaban qué hacer y tomaban posiciones. De manera casi imperceptible, el franquismo empezaba a descomponerse. Uno de los primeros que lo intuyó fue el coronel San Martín. A principios de 1971 la OCN editó el Libro Rojo de la Subversión, en el que se analizaba tanto la oposición antifranquista como "los fallos y deficiencias del Sistema". San Martín recordaba que en las conclusiones del trabajo "se recomendaban una serie de medidas, políticas naturalmente, terminando con la célebre frase de Ossorio [Ángel Ossorio y Gallardo] en su libro sobre Cambó [Francisco Cambó y Batlle] (II tomo): 'Los regímenes políticos no se derrumban ni perecen por el ataque de sus adversarios, sino por la aflicción y el alejamiento de los que deberían sostenerlos "',59.

\footnotetext{
58 Cassinello: 25-26.

59 San Martín 1983: 38.
} 


\section{Referencias bibliográficas:}

Arteaga 1971: F. de Arteaga, "ETA" y el proceso de Burgos. (La quimera separatista) (Guadalajara, 1971).

Cañellas 2015: A. Cañellas, Alfredo Sánchez Bella, un embajador entre las Américas y Europa. Diplomacia y politica informativa en la España de Franco (1936-1973) (Gijón, 2015).

Cardona 1990: G. Cardona, El problema militar en España (Madrid, 1990).

Casanellas 2014: P. Casanellas, Morir matando. El franquismo ante la práctica armada, 1968-1977 (Madrid, 2014).

Casanova 2010: I. Casanova, ETA 1958-2000: Medio siglo de historia (Tafalla, 2010).

Cassinello: A. Cassinello, La huella que deja el viento al pasar (inédito, 19881990).

Casquete 2012: J. Casquete, "Proceso de Burgos", en S. Pablo de et alii, Diccionario ilustrado de símbolos del nacionalismo vasco (Madrid, 2012).

Castro 1998: R. Castro, Juan María Bandrés. Memorias para la paz (Madrid, 1998).

Chuliá 1997: M. E. Chuliá, Evolución silenciosa de las dictaduras: el régimen de Franco ante la prensa y el periodismo (Universidad Complutense, 1997).

Cierva 1978: R. de la Cierva, Historia del franquismo: aislamiento, transformación, agonía (1945-1975) (Barcelona, 1978).

Delgado 2005: J. Delgado, Los grises. Victimas y verdugos del Franquismo (Madrid, 2005).

Domínguez 1998: F. Domínguez, ETA: Estrategia organizativa y actuaciones, 1978-1992 (Bilbao, 1998).

Egaña 1996: I. Egaña, Diccionario histórico-político de Euskal Herria (Tafalla, 1996).

Fernández 2016: G. Fernández, La voluntad del gudari. Génesis y metástasis de la violencia de ETA (Madrid, 2016).

Fernández y Domínguez 2018: G. Fernández y F. Domínguez (coords.), Pardines. Cuando ETA empezó a matar (Madrid, 2018).

Franco 1976: F. Franco Salgado-Araujo, Mis conversaciones privadas con Franco (Barcelona, 1976).

Fuente 1998: L. de la Fuente, Valió la pena. Memorias (Madrid, 1998).

Garmendia 1996: J. M. Garmendia, Historia de ETA (San Sebastián, 1996).

Garmendia 2006: J. M. Garmendia, "ETA: nacimiento, desarrollo y crisis (1959-1978)", en A. Elorza (coord.), La historia de ETA (Madrid, 2006).

Gil 1981: V. Gil, Cuarenta años junto a Franco (Barcelona, 1981). 
Halimi 1972: G. Halimi, El proceso de Burgos (Caracas, 1972).

Jáuregui 2006: G. Jáuregui, "ETA: orígenes y evolución ideológica y política", en A. Elorza (coord.), La historia de ETA (Madrid, 2006).

Jáuregui y Vega 1984: F. Jáuregui y P. Vega, Crónica del antifranquismo (2) (Barcelona, 1984).

Letamendia 1975: F. Letamendia, Historia de Euskadi: el nacionalismo vasco y ETA (París, 1975).

Letamendia 1994: F. Letamendia, Historia del nacionalismo vasco y de ETA (San Sebastián, 1994).

López Rodo 1979: L. López Rodo, La larga marcha hacia la Monarquía (Barcelona, 1979).

Lurra 1978: Lurra, Burgos: juicio a un pueblo (San Sebastián, 1978).

Martín García 2009: O. J. Marín García, "Separatismo, subversión y violencia colectiva en el País Vasco (1968-1976). Nuevas perspectivas del cambio político desde las fuentes del Foreign Office", en M. Ortiz (coord.), Culturas políticas del nacionalismo español. Del franquismo a la Transición (Madrid, 2009).

Molinero e Ysàs 2008: C. Molinero y P. Ysàs, La anatomía del franquismo. De la supervivencia a la agonía, 1945-1977 (Barcelona, 2008).

Morán 1982: G. Morán, Los españoles que dejaron de serlo. Cómo y por qué Euskadi se ha convertido en la gran herida histórica de España (Barcelona, 1982).

Muñoz 1982: A, Muñoz, El terrorismo en España (Barcelona, 1982).

Núñez 1993: L. Núñez (coord.), Euskadi Eta Askatasuna. Euskal Herria y la Libertad (Tafalla, 1993).

Onaindia 2001: M. Onaindia, El precio de la libertad. Memorias (1948-1977) (Madrid, 2001).

Pablo 2015: S. de Pablo, La patria soñada. Historia del nacionalismo vasco desde su origen a la actualidad (Madrid, 2015).

Palacios 1996: J. Palacios, Los papeles secretos de Franco: de las relaciones con Juan Carlos y don Juan al protagonismo del Opus (Madrid, 1996).

Preston 2002: P. Preston, Franco. “Caudillo de España” (Barcelona, 2002).

Rodríguez 1994: J. L. Rodríguez Jiménez, Reaccionarios y golpistas. La extrema derecha en España: del tardofranquismo a la consolidación de la democracia (1967-1982) (Madrid, 1994).

Sainz 1993: J. Sainz, Testimonios de un policía español (autoedición, 1993).

Salaberri 1971: K. Salaberri, El proceso de Euskadi en Burgos. El sumarísimo 31/69 (París, 1971).

San Martín 1983: J. I. San Martín, Servicio especial. A las órdenes de Carrero Blanco (de Castellana a El Aaiún) (Barcelona, 1983). 
Sullivan 1988: J. Sullivan, El nacionalismo vasco radical, 1959-1986 (Madrid, 1988).

Tusell 1993: J. Tusell, Carrero. La eminencia gris del Régimen de Franco (Madrid, 1993).

Unzueta 1988: J. L. Unzueta, Los nietos de la ira. Nacionalismo y violencia en el País Vasco (Madrid, 1988).

Uriarte 1997: E. Uriarte, El tratamiento periodístico sobre ETA desde 1964 a 1975 (UPV-EHU, 1997).

Uriarte 2005: E. Uriarte, Mirando atrás. Del proceso de Burgos a la amenaza permanente (Barcelona, 2005).

Uriarte 2013: E. Uriarte, Tiempo de canallas. La democracia ante el fin de ETA (Vitoria, 2013).

Zaragoza 1993: A. Zaragoza, "Aproximación al Proceso de Burgos a partir del Archivo de la Presidencia del Gobierno", en J. Tusell, S. Sueiro, J. M. Marín y M. Casanova, El régimen de Franco, 1936-1975: política y relaciones exteriores (Madrid, 1993). 
